\title{
Selected Aspects of Pavement Texture Influence on Tire Rolling Resistance
}

\author{
Jerzy Ejsmont *(i) and Slawomir Sommer
}

Automotive and Military Technology Division, Faculty of Mechanical Engineering and Ship Technology, Gdansk University of Technology, 11/12 Gabriela Narutowicza St., 80-233 Gdansk, Poland; ssommer@pg.edu.pl * Correspondence: jejsmont@pg.edu.pl

check for updates

Citation: Ejsmont, J.; Sommer, S. Selected Aspects of Pavement Texture Influence on Tire Rolling Resistance. Coatings 2021, 11, 776. https:// doi.org/10.3390/coatings11070776

Academic Editor: Malal Kane

Received: 26 May 2021

Accepted: 25 June 2021

Published: 29 June 2021

Publisher's Note: MDPI stays neutral with regard to jurisdictional claims in published maps and institutional affiliations.

Copyright: (c) 2021 by the authors. Licensee MDPI, Basel, Switzerland. This article is an open access article distributed under the terms and conditions of the Creative Commons Attribution (CC BY) license (https:// creativecommons.org/licenses/by/ $4.0 /)$.
Abstract: Tire rolling resistance has a significant influence on fuel consumption in cars and trucks and on $\mathrm{CO}_{2}$ emissions. Rolling resistance depends on the tire construction, pavement texture and stiffness, as well as environmental and traffic conditions. This article presents a pilot study on the impact of pavement texture on the rolling resistance of passenger car tires. Reasons why Mean Profile Depth is not a good descriptor of pavement characteristics from the point of view of rolling resistance are presented, and an experimental method which takes into account tire deformation on texture and partial enveloping is described. A method based on testing the volume and depth of tire tread deformation is also proposed.

Keywords: tire; road pavement; texture; rolling resistance; enveloping; measurements

\section{Introduction}

Due to the need to slow climate changes, it is necessary to reduce energy consumption, especially energy that is not renewable and comes from fossil fuels. According to [1], in 2016 , crude oil production was approximately 4.4 billion tones, of which approximately $60 \%$ was converted into motor fuels (gasoline and diesel). As the vast majority of this type of fuel is consumed by motor vehicles, this means that reducing vehicle fuel consumption by only $1 \%$ can result in a reduction of crude oil consumption by about 15-20 million tons per year. According to [2], annual greenhouse gas emissions are around 50 billion tones, of which road transport accounts for around $12 \%$, that is, 6 billion tones. A $1 \%$ reduction in fuel consumption thus means a reduction in emissions of around 60 million tonnes per year.

Rolling resistance of car tires is one of the most important components of the total resistance acting on motor vehicles. It is assumed that for low and medium speed driving (30-90 km/h), reducing the total resistance acting on a vehicle by $1 \%$ (with similar impact on fuel consumption) requires reducing the rolling resistance of tires by $3 \%-4 \%$ [3].

Tire rolling resistance depends on many factors, including tire construction, road surface characteristics, weather conditions and traffic parameters. The subject of this article is the influence of the road surface, in particular the influence of the texture of the road pavement. In many available publications [4-7] there have been attempts to perform the assessment of the influence of the pavement on the rolling resistance on the basis of Mean Profile Depth (MPD) [8], but in most cases correlation between rolling resistance and MPD was not very high. A comprehensive state of the art review was published by Wills, Robbins and Thompson [9] and they concluded that: "... the greater the texture of the pavement, the greater the rolling resistance" and "In many cases, texture could change the rolling resistance of pavement by 5 to 10 percent".

Understanding the relationship between pavement texture and rolling resistance is important because it enables multi-criteria optimization of the pavement. The texture affects, among others, tire/road noise, grip (wet and dry), tire wear and driving comfort. Since precise measurements of rolling resistance in road conditions are very difficult to 
perform [10], it is advantageous to determine whether the pavement will promote low rolling resistance based on its geometrical characteristics. In many countries development work is currently underway to create environmentally friendly pavements, that is, pavements that reduce vehicle noise and contribute to fuel consumption reduction [11]. Multi-criteria optimization of the pavement is difficult because there are many factors that influence pavement characteristics in a complicated way. For example, on surfaces with high MPD, with little rainfall, water is collected in dip pits and voids. This reduces the risk of hydroplaning and does not require intensive pumping of water by the tire tread, which is also beneficial for rolling resistance. Such a pavement, however, stores water for a longer period of time, and this in turn leads the longer lasting pavement dampness after the rain has stopped, but the water stored in the road cavities cools the tires and this in turn significantly increases the rolling resistance [12].

Undoubtedly there is a strong relationship between pavement texture and rolling resistance, but the pavement texture must be parameterized in the way the tire "sees" it. The MPD is a purely geometric texture parameter that has been designed to describe the texture in terms of its effect on tire/road noise where volume of cavities between tread rubber and pavement surface plays an important role. MPD may also indicate the surface's ability to accumulate water during low-intensity rainfall. Unfortunately, the MPD does not describe the deformation of the tread elements well, because the tread rubber does not "sense" the exact shape of texture of the surface during contact, but in most cases the contact is restricted only to the summits of the texture. This phenomenon is called tire enveloping [7].

In Figure 1 such exaggerated cases of enveloping are presented. The green profile represents a rather smooth pavement $(\mathrm{MPD}=0.5 \mathrm{~mm})$ that ascertains full contact with tire tread. The red profile represents a very "aggressive pavement" (MPD $=5 \mathrm{~mm}$ ) that interacts with tread rubber only in the most elevated regions (summits). In this article, the authors use the term "aggressive pavement" to mean a pavement with high, positive texture [13] dominated by summits not by pots, with harsh edges and sharp peaks of the aggregate. Such a surface usually shows very good friction, especially in wet conditions and when it is covered with a thin layer of ice or snow, but is noisy and has high rolling resistance. It seems reasonable to speculate that for rolling resistance, which is related to tire deformations, change of MPD (provided that the shape of peaks is similar) between these two extreme cases will not be important; thus, rolling resistance will not correlate with MPD.

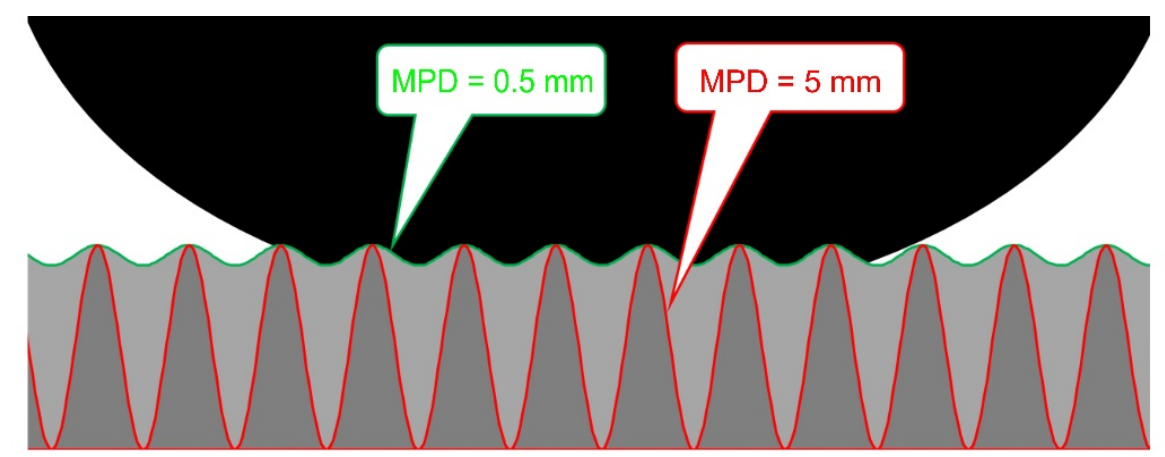

Figure 1. Tire enveloping on two very different road pavements.

The above statement, however, conflicts with observations of nearly all researchers [9] that a certain correlation between those two parameters exists after all. According to research carried at the Gdansk University of Technology [7] the correlation is, however, not just a simple result of higher MPD but it is caused by different shape of the "summit regions" of typical textures with high MPD (coarse pavements) in comparison to smooth pavements. Such aggressive pavements usually have sharp, widely spaced aggregate which, in order to transfer the pressure, penetrates the tread elements much more deeply. 
A lower contacting area and steeper slopes of the mineral aggregate edges cause local strains and deformations to be very high. Due to the hysteresis of the tread material and the nonlinear phenomena typical of it, the increase in deformation leads to substantial increase in energy losses, which results in increase of rolling resistance. This is visualized in Figure 2. So, in the authors' opinion, the increase of rolling resistance on pavements with high MPD is not due to the fact that the cavities (pits) are deeper and more specious but because the summits are sharper and less congested.
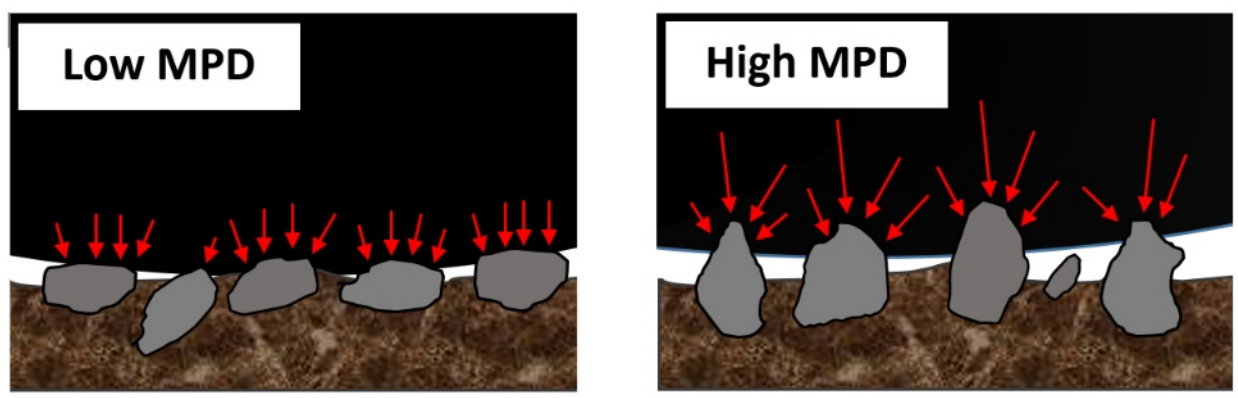

Figure 2. Tire enveloping on two very different road pavements.

\section{Materials and Methods}

In order to determine the effect of texture on rolling resistance, it is necessary to conduct road and laboratory tests using surfaces with realistic textures. In the case of laboratory tests, the main difficulty is related to the fact that international standards [14-17] require testing on smooth steel drums so the vast majority of research institutions only have such devices. However, the Gdańsk University of Technology (GUT, Gdańsk, Poland) laboratory uses a roadwheel facility with an external drum with a diameter of $2.0 \mathrm{~m}$ on which replicas of road surfaces with matching texture can be mounted (see Figure 3). Thanks to this, a high degree of measurement representability is obtained, as the only serious disturbance of the tire/road interaction is the curvature of the drum. The facility is located in an isothermal chamber, which enables rolling resistance tests to be carried out at temperatures from -15 to $+30^{\circ} \mathrm{C}$.

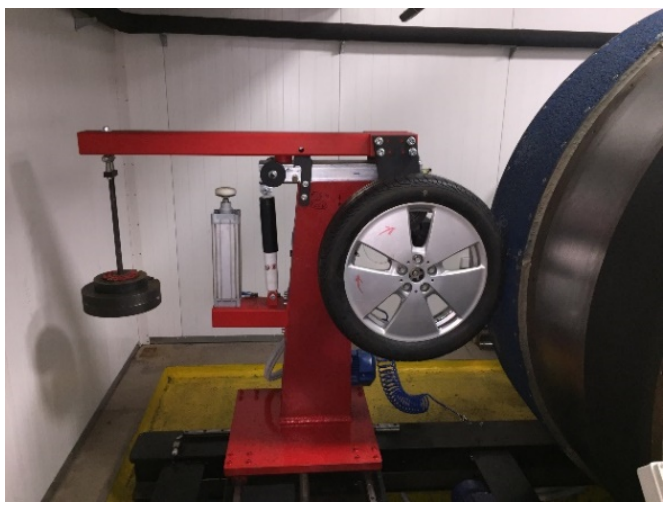

Figure 3. Roadwheel facility for tire rolling resistance measurements.

For road tests, however, more complex equipment is needed because the popular coastdown tests, used a long time ago, have questionable accuracy and are very impractical to carry out, at least on public roads. At GUT, a specialized $\mathrm{R}^{2} \mathrm{Mk} .2$ test trailer (manufactured by GUT, Miami, FL, USA) is used for rolling resistance tests, which was specially made for this purpose and has very advanced systems, reducing the impact of unavoidable disturbances like road grade, speed deviations, ruts, etc. (see Figure 4). There are only a few test trailers in the world that can measure rolling resistance, and the $\mathrm{R}^{2} \mathrm{Mk} .2$ trailer is possibly the most technically advanced and efficient [18]. 


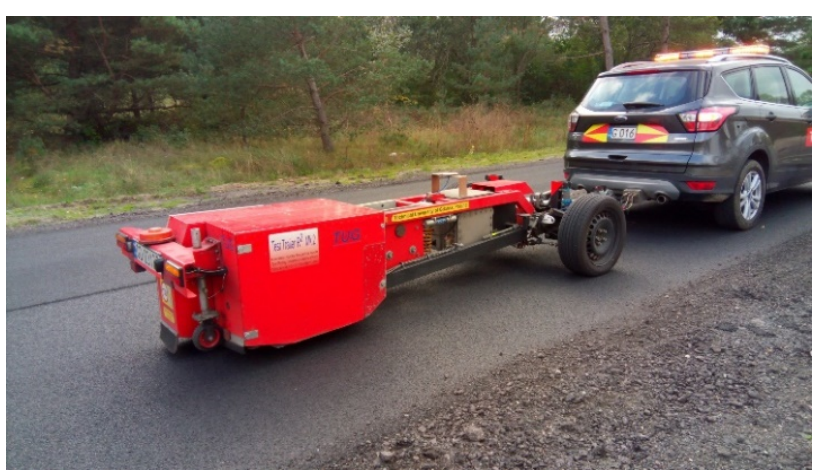

Figure 4. Test trailer $\mathrm{R}^{2} \mathrm{Mk} .2$ for tire rolling resistance measurements.

The oscillatory engineering method, which is described in [19], can also be used to roughly evaluate the influence of pavement texture on the rolling resistance. This method examines the oscillations generated after the tire is dropped onto the surface sample (see Figure 5). Energy dissipation during cyclic tire deflections causes decay of oscillations, which may be used as a specific measure of rolling resistance. This method has been used for some of the experiments described in this article.

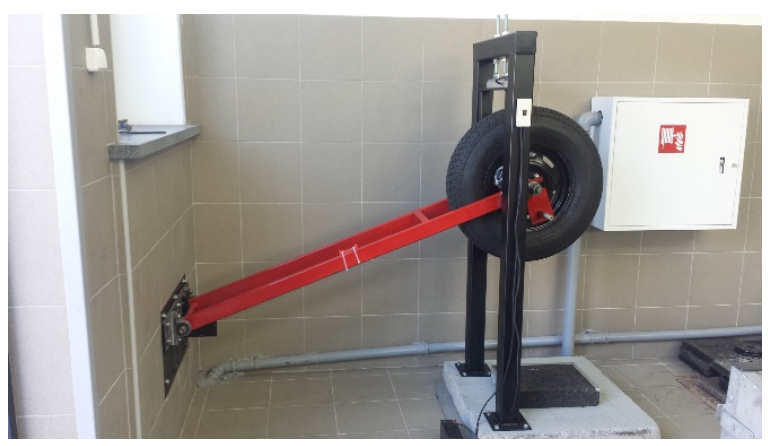

Figure 5. Facility to test dissipation of energy in tire by oscillation method.

In order to test the tread rubber enveloping texture of a given road pavement it is necessary to use special, non-standard test methods. The methods based on pressuresensitive film do not allow for the 3-D observation of the contact zone of the tire with the road surface and are practically useless on more aggressive surfaces, such as surface dressing, because the film is pierced by the sharp edges of the aggregate. For the needs of such tests, a special method was developed at GUT, based on casting an imprint of the tire/road contact in self-vulcanizing rubber.

The tested road surface is covered with a liquid, low-viscosity, self-vulcanizing rubber, which is extruded by the tire pressed against the pavement by a given load (exactly in the same way as rainwater is extruded from the tire/pavement footpath). The rubber is in a liquid state and the hardening process takes over an hour, so the rubber does not carry any load as it can flow out freely. As a consequence, the tire only rests on the rigid road surface and rubber remains only in places where there is no tire/pavement contact. After the rubber has hardened and the tire has been removed from the casting, fragments that were in direct contact with the tire protrude from the hardened rubber plane where there was no such contact. The method can be applied to virtually all types of road surfaces. In very few cases, it may be necessary to assist in displacing the liquid rubber by drilling drainage holes through the pits of the pavement sample. Figure 6 shows the process of obtaining castings and Figure 7 shows a cast made on an artificial pavement consisting of evenly spaced pyramids. 


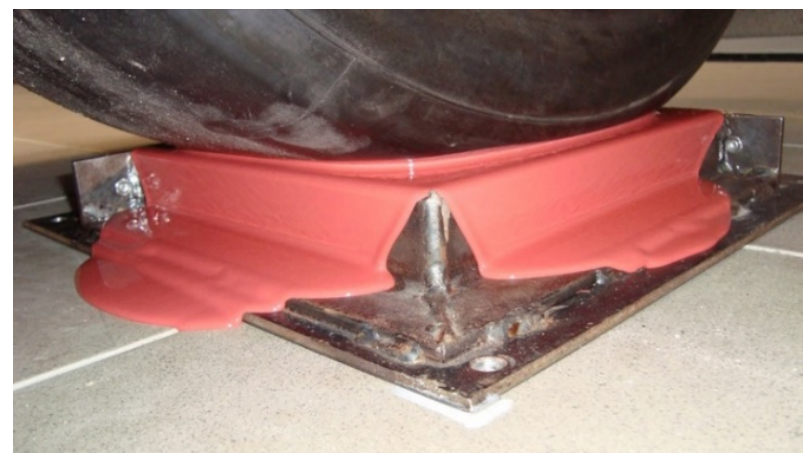

Figure 6. Making the contact deformations mold.

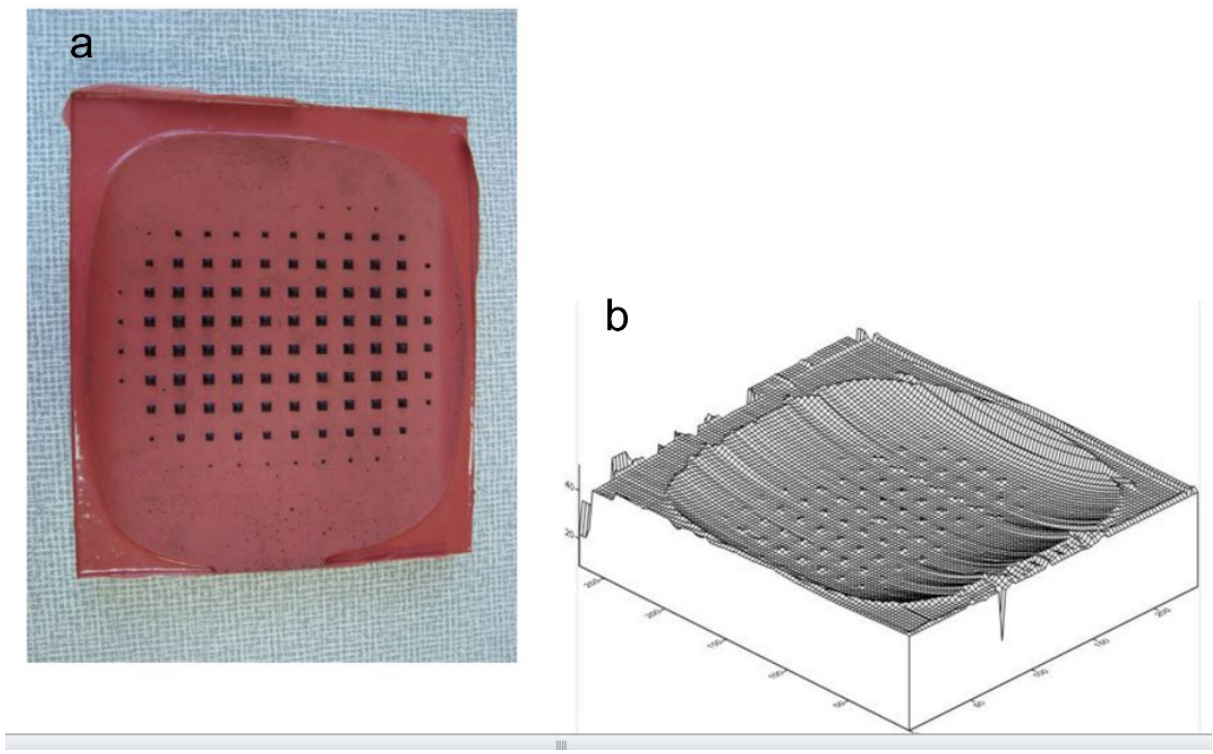

Figure 7. Contact deformations obtained on experimental pavement composed with equally spaced pyramids: (a) rubber casting; (b) digital model.

An advantage of this method is its great simplicity and the possibility of preserving the shapes of contact deformations of the tire tread, which can then be analyzed qualitatively and quantitatively. The most important disadvantage of the method is that static deformations that are registered might not necessarily be the same as in the case of driving, when the interface between the tire and the road is very short-lived and the tread material does not have time to fully settle on the pavement (tread rubber has hysteresis depending on excitation frequency). Nevertheless, in the opinion of the authors, the advantages of the method outweigh its disadvantages.

In order to determine the time characteristics of the tire tread deformation process forced by the pavement protrusions, a special device was developed (see Figure 8), in which a pneumatic actuator drives a penetrator of a given shape into the tread of a tire resting on a flat steel plate (the penetrator is marked with an arrow in the figure). It is possible to change the shape of the penetrator and even to use penetrators made of small fragments of the actual road surface (see Figure 9). Thanks to this device it is possible to determine the relationship between the force acting on the penetrator and depths of rubber deflection, and how quickly the rubber deforms. 


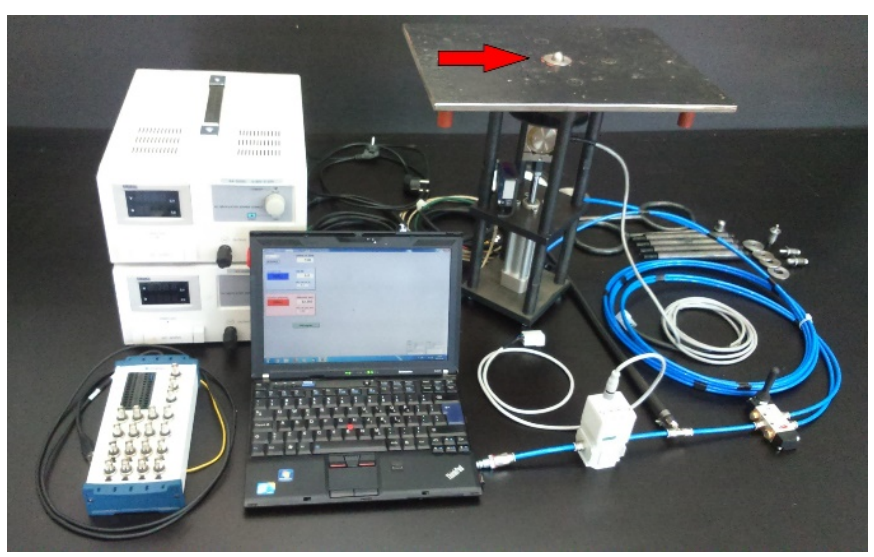

Figure 8. Device for investigation of tire tread deflections caused by pavement protrusions.

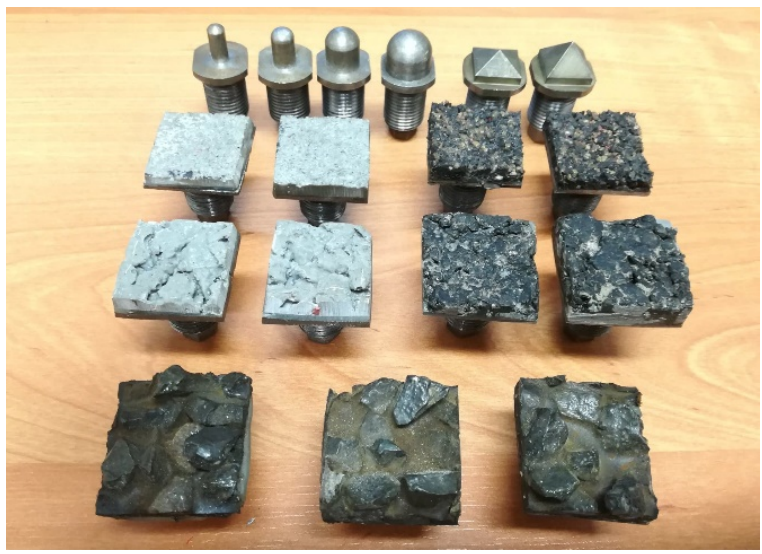

Figure 9. Different penetrators used in this study.

The applied pneumatic system provides a relatively high speed of free penetrator extension which is comparable to the speed with which the protrusions of the pavement are pressed into the rubber of the tread at slow speed driving.

\section{Results}

\subsection{Qualitative Investigation of Enveloping Properties on Two Different Road Pavements}

In order to roughly determine the influence of the surface type and the type of rubber mixture in the tread area on the enveloping phenomenon, tests of tire tread deformations were carried out for two road surfaces, which were very different in terms of texture. They were Stone Mastics Asphalt (Code name SMA8), which is a very popular, relatively smooth road surface, and Surface Dressing (code name APS) with a very aggressive texture. The SMA8 pavement had MPD $=1.58 \mathrm{~mm}$, and the APS pavement had MPD $=4.48 \mathrm{~mm}$. The tests were carried out for two test tires with smooth treads made of rubber mixtures of very different hardness. These were tires intended for mountain races where the "HARD" tread had a hardness of $68^{\circ} \mathrm{Sh}$ at $21^{\circ} \mathrm{C}$ and the "SOFT" tread had hardness of $44^{\circ} \mathrm{Sh}$. It is necessary to stress that sport tires, especially designed for mountain races, are optimized for traction, not rolling resistance, so tread rubber has fairly big hysteresis, at least in the high excitation frequency range. Addition of silica makes it possible to reduce hysteresis in low frequency range (good for rolling resistance) maintaining high hysteresis in the high frequency range (good for traction) [20]. Nevertheless, despite the specific characteristics of sports tires, they allow testing of compounds with a hardness that is covers, or even goes beyond, the range used in commercial tires. A big advantage for this particular investigation is that tested tires had smooth tread (slick). The tests were performed with the method of rubber impressions described in Chapter 2. 
Figure 10 presents partial contact area between the test tires and the SMA8 surface. The limits of contact area between the tested tires and the road are clearly visible. The penetration of the pavement into the tire tread is greater for the SOFT tread than for the HARD tread. This is visible in Figure 11 showing the cross-section of the pavement and the cross-sections of deformed tire treads along the line marked in Figure 10.
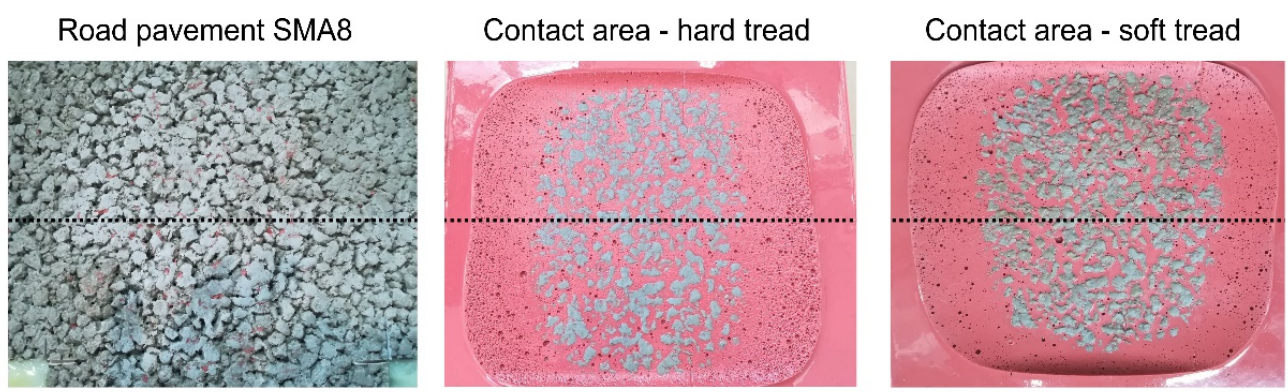

Figure 10. View of SMA8 pavement and contact area of HARD and SOFT treads.

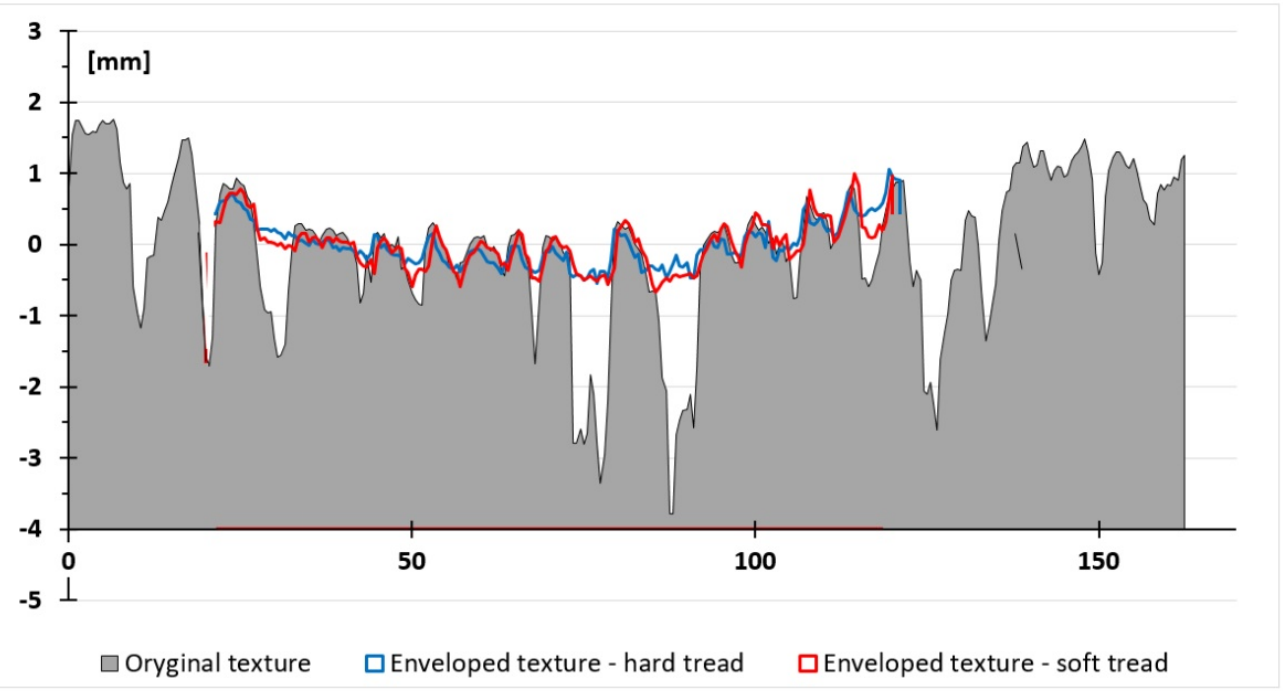

Figure 11. Profile of SMA8 pavement and profiles of tread deflections of HARD and SOFT tires.

It should be taken into account that making a rubber impression takes considerable time, so the pressure of the tire on the pavement is static. When the tire rolls on the road, the contact duration is very short (at $80 \mathrm{~km} / \mathrm{h}$ only a few milliseconds), which probably makes the penetration even smaller. So, it seems safe to say that the actual aggregate penetration into the tread is somewhat smaller during driving than that obtained in the static test reported here.

Similar tests were also carried out for the APS pavement and the results are shown in Figure 12. In the case of this surface, contact occurs only in the region of the summits of the aggregate, over a very small area. This small area, however, is compensated (in terms of caring the load) by the deep penetration into the tread rubber. This penetration is, of course, greater for the SOFT tread than for the HARD tread. This is presented in Figure 13 showing the cross-section of the pavement and the cross-sections of deformed tire treads along the line marked in Figure 12. It can be presumed that for such deep penetrations the time factor is even more important than for the situation with the SMA8 surface, i.e., the actual contact of the tire with the surface is even smaller. 

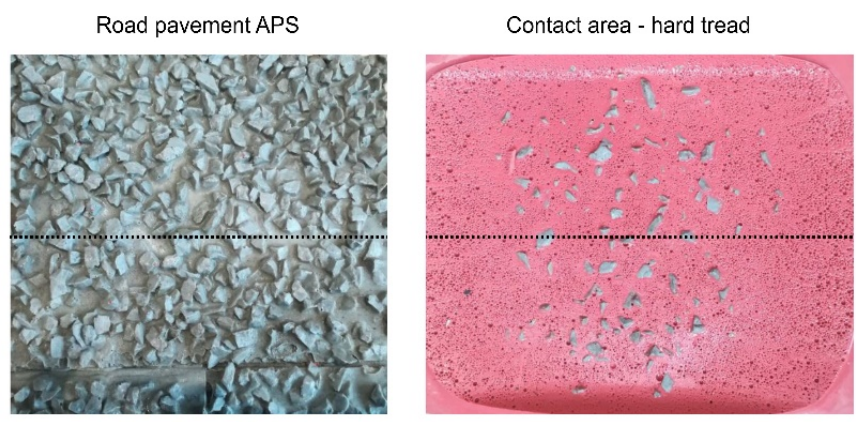

Contact area - soft tread

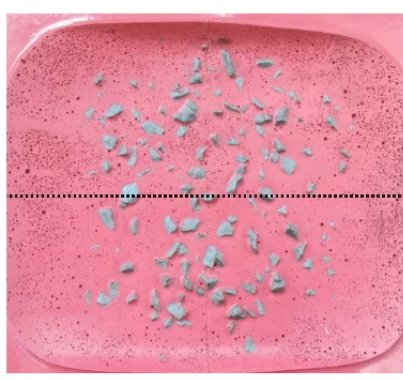

Figure 12. View of APS pavement and contact area of HARD and SOFT treads.

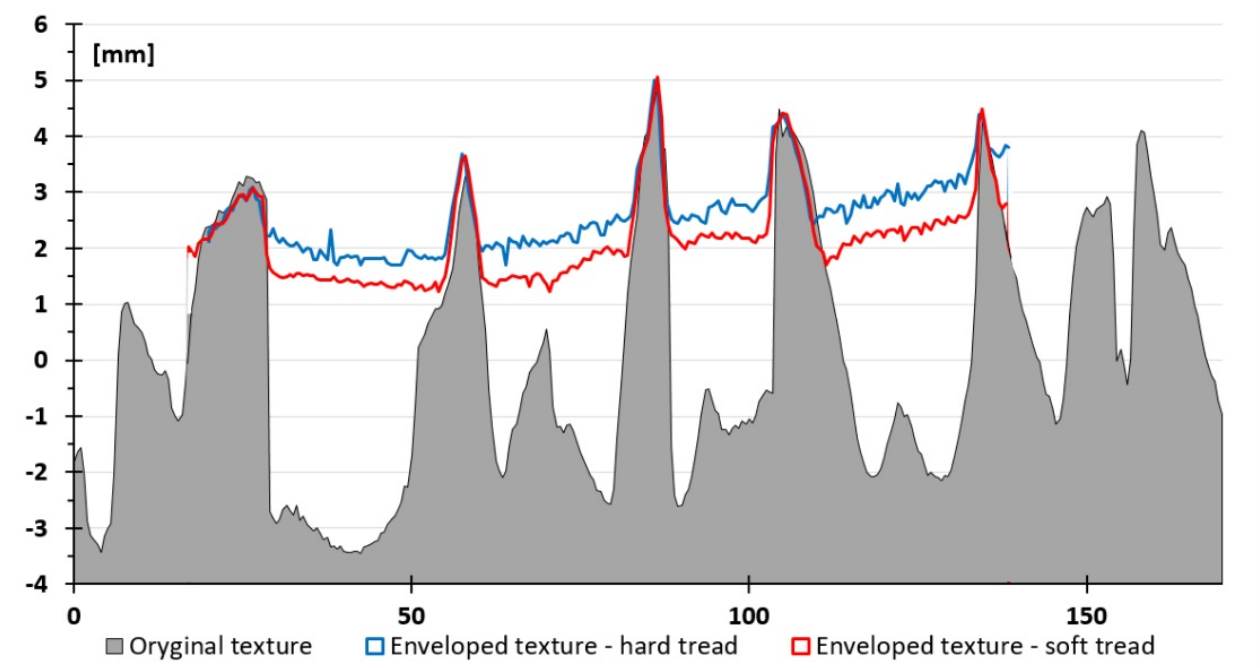

Figure 13. Profile of APS pavement and profiles of tread deflections of HARD and SOFT tires.

For all cases reported above the estimation of "enveloped MPD" was carried out based on tire deflection profiles presented in Figures 11 and 13. The values of MPD are presented in Table 1. On average, due to restricted enveloping, even for relatively smooth pavement SMA8 the tires "sense" only 70\% of the nominal MPD. For very aggressive Surface Dressing APS is only $45 \%$ of nominal MPD.

Table 1. Comparison of "enveloped MPD" for tested slick tires with MPD calculated on the base of raw pavement profile.

\begin{tabular}{ccc}
\hline MPD (mm) & SMA8 & APS \\
\hline "Raw" (based on pavement profile) & 1.58 & 4.48 \\
"Enveloped" for SOFT tire & 1.13 & 2.22 \\
"Enveloped" for HARD tire & 1.11 & 1.81 \\
\hline
\end{tabular}

For confirmation of the assumption that profiles made of self-curing rubber reproduce the deformation of the tire well, and that during dynamic interaction between tread and pavement the deflections of the tread are not bigger than shown by rubber castings, the oscillatory engineering method described above was used. The Coefficients of Energy Losses (CEL) [19] obtained during the tire tests on the original SMA8 and APS surface samples were compared with measurements on samples where the profile depth was reduced artificially by pouring liquid resin to the level corresponding to the enveloped MPD. Table 2 presents the values of the CEL before and after "flattening" the pavement texture. As shown in Table 2, the values of these coefficients have not changed, which means that the conditions of contact between the tire and the road have also not changed. 
This implies that the texture pits eliminated by filling with resin did not take part in the transmission of tire load, even in dynamic conditions.

Table 2. Comparison of CEL for tested slick tires tested on raw APS sample and APS sample with reduced texture.

\begin{tabular}{ccc}
\hline CEL [-] & SOFT Tread & HARD Tread \\
\hline "Raw" texture & 0.0143 & 0.0207 \\
Texture reduced to value of enveloped MPD & 0.0143 & 0.0203 \\
\hline
\end{tabular}

The deformations of rubber resulting from the pressure of aggregate summits depend largely on both the hardness of the compound and the shapes of the summits. Figure 14 presents the penetration characteristics of two differently shaped penetrators pressed into the SOFT and HARD tire. As the figure shows, the pyramid-shaped penetrator penetrates the rubber more quickly and more deeply than the spherical-shaped penetrator. This confirms the assumption that the shape of the aggregate is very important for the deflection of the tread material, thus, also for rolling resistance.

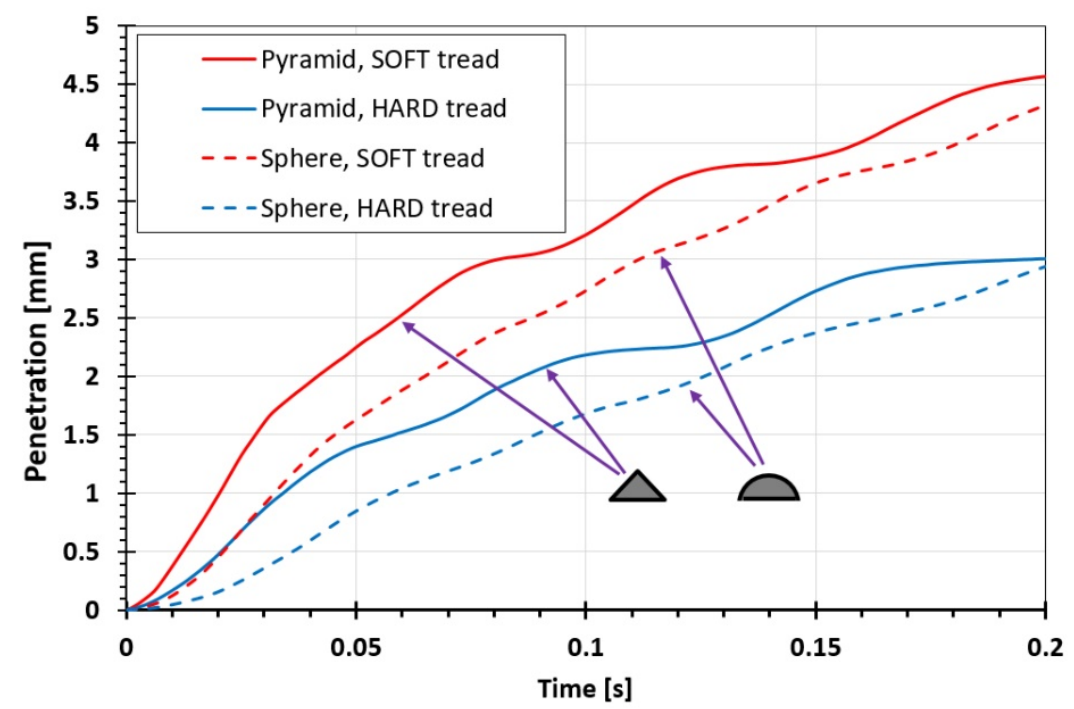

Figure 14. Deflection of tire tread by penetrators of different shape.

\subsection{Results of Rolling Resistance Tests}

As the vast majority of tire development tests are carried out in the laboratory, a significant problem is to confirm that the results obtained on replicas of road surfaces are representative and reflect well the results obtained during road tests. In Figure 15 comparison of road and drum measurements is presented. Five passenger car tires of size 205/55R16 were tested on the road pavement SMA8 and on its replica road surface mounted on a drum. The replica was cast 7 years ago on this particular road so its structure replicates brand new SMA8. Unfortunately, after 7 years of use, despite low traffic volume on this road, the MPD value lowered from initial value of 1.55 to $0.85 \mathrm{~mm}$. During measurements the capped inflation pressure principle was used ( $210 \mathrm{kPa}$ for cold tire). The figure indicates very good correlation between road and drum results. Lower rolling resistance values obtained during road measurements should be attributed to lower MPD.

In Table 3 results of rolling resistance measurements performed for SOFT and HARD slick tires used for experiments reported in this article are presented. For both tires there is $50 \%$ increase of Coefficient of Rolling Resistance (CRR) on APS pavement in relation to SMA8. At the same time, for both surfaces, the difference between the rolling resistance for HARD and SOFT tires is about $15 \%$. At first glance this may look strange (and contrary to the considerations made above) that a SOFT tire experiencing deeper tread deflections 
caused by pavement texture exhibits lower rolling resistance than a HARD tire. This is, however, a result of considerably lower strains in soft rubber which are associated with the flattening of the tire torus in the area of contact with the road. In tires with a conventional tread pattern, the grooves, especially transverse grooves, make the tire more elastic, reduce the stresses and, thus, also the rolling resistance. The slick tire, however, lacks a tread pattern, and therefore the hard, continuous tread layer is subjected to very high stresses. Additionally, during sports driving, the tires heat up much more than during test drives, and even the hard compound becomes softer due to high temperature. Tires with conventional tread pattern are unfortunately not suitable for studies utilizing casting of footprints as the tread grooves interfere with the analysis.

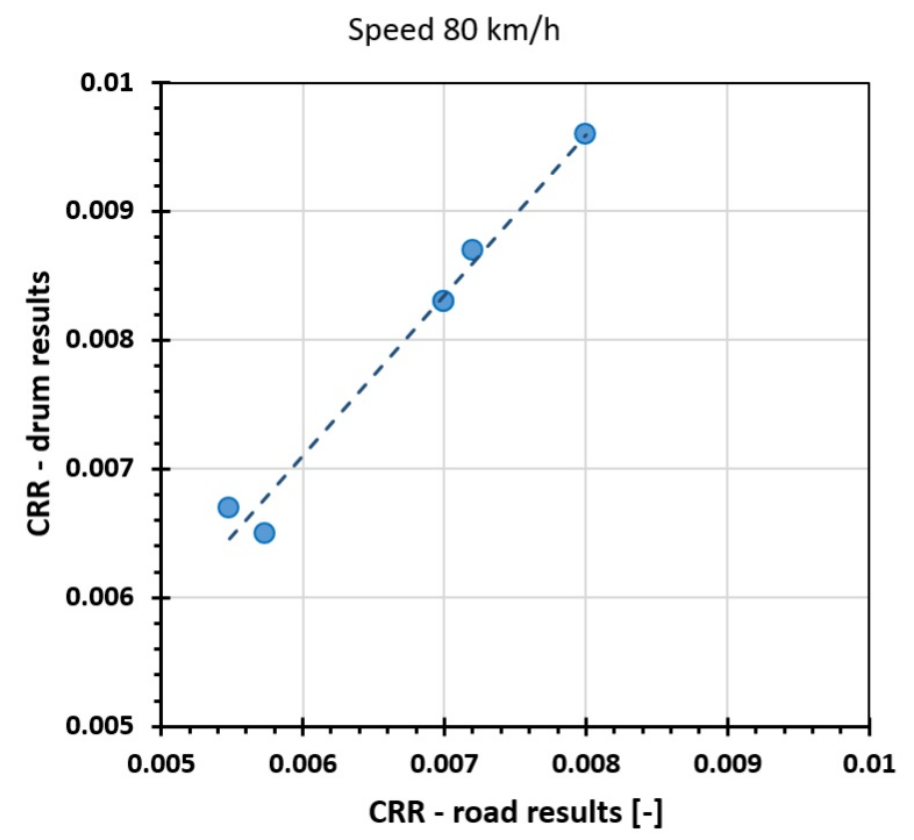

Figure 15. Comparison of Coefficients of Rolling Resistance measured by road method on SMA8 pavement and by drum method on SMA8 replica.

Table 3. Coefficients of Rolling Resistance of SOFT and HARD slick tires tested according to ISO standard on replicas SMA8 and APS at $80 \mathrm{~km} / \mathrm{h}$.

\begin{tabular}{ccc}
\hline CRR [-] & SOFT Tread & HARD Tread \\
\hline SMA8 & 0.0102 & 0.0119 \\
APS & 0.0158 & 0.0178 \\
\hline
\end{tabular}

To compare the relation between CRR and MPD a set of six passenger car tires was tested on seven replica road surfaces covering MPD range from 0.42 up to $4.75 \mathrm{~mm}$. On each replica values of CRR obtained at $80 \mathrm{~km} / \mathrm{h}$ were averaged and plotted against corresponding MPD (see Figure 16). During these tests, the air temperature was $25^{\circ} \mathrm{C}$ and the regulated inflation pressure principle was used. It is apparent that there is a rather weak relation between rolling resistance and conventionally established ("classical") MPD. One must observe that MPD value of about $5 \mathrm{~mm}$ is measured only on very aggressive pavements and in many investigations such extreme pavements were not included. For all tested replicas values of enveloped MPD were also evaluated and are presented in Figure 16 (green markers and line). Measured CRR showed much stronger relation to enveloped MPD than to the classical MPD. 


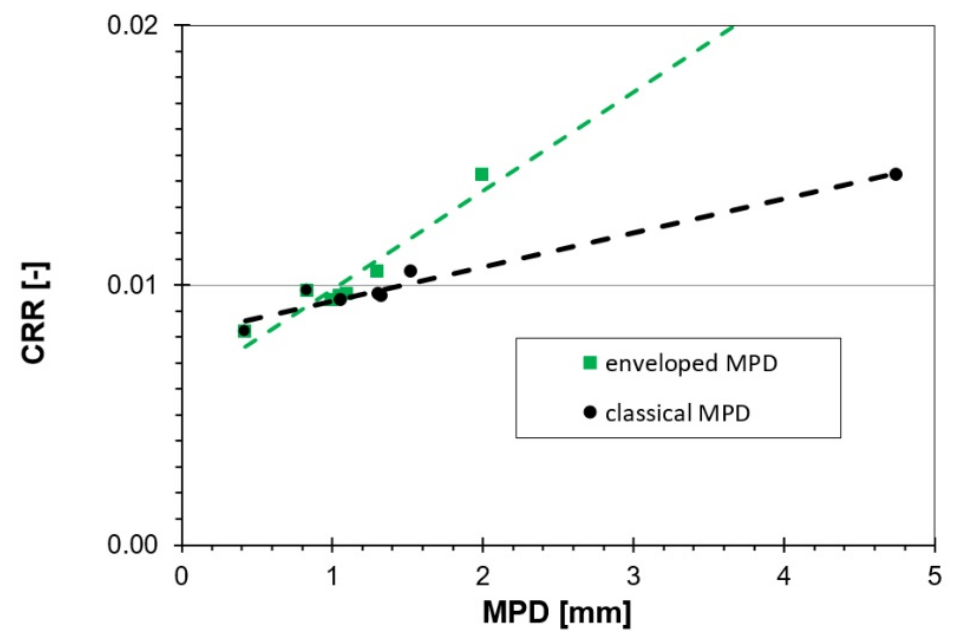

Figure 16. Comparison of relations between MPD (evaluated in the classical method and using enveloping correction) and Coefficient of Rolling Resistance.

\section{Discussion}

Due to the fact that the research presented in this article is a "pilot study" it is not possible to unequivocally define how the optimal, easy to evaluate parameter describing pavement influence on rolling resistance should look. As can be seen from the considerations presented above, the rolling resistance cannot correlate well with the MPD evaluated in a classical way, as the tire in most cases only partially envelops the pavement texture. The conducted experiments showed that experimental estimation of the enveloped MPD is possible and that it allows elimination of those texture regions that do not come into contact with the tire. Although the method of making rubber castings is laborious, it allows for a more realistic estimate of the enveloped MPD value, just as in the way the tire "feels" it.

The authors believe that a completely different method of pavement characterization in respect to rolling resistance could also be used, which takes better account of the pavement texture properties that are important for energy losses. The proposed method examines the relationship between the penetration depth of the texture summits and the volume of deformed rubber. If the pavement has the structure as shown in Figure 10 (for example like SMA8), to obtain deformation of significant volume, even a small penetration depth is enough. If, on the other hand, the pavement structure is as shown in Figure 12, then deep penetration is necessary to achieve deformation of the same volume of rubber (as is the case with the APS pavement). It can, therefore, be speculated that the characteristics of the deflected rubber volume as a function of the penetration depth can classify the surfaces in terms of their "aggressiveness" influencing the rolling resistance.

In Figure 17, the principle of such texture evaluation is described. In the first step, using the $3 \mathrm{D}$ recording of the pavement texture, the analyzed area should be determined. In the study discussed in this article, each time this was a $50 \mathrm{~mm} \times 50 \mathrm{~mm}$ square located in the region of the center of the tire imprint. For this square, the level of the highest summit is established (in Figure 17 marked as $h=0$ ) as well as the lowest pit determined by the enveloped tire imprint (marked as $h_{\max }$ ). Then, starting from $h=0$ up to $h_{\max }$, the total volume of unevenness that penetrates the tread is determined $\left(\mathrm{V}=\mathrm{V}_{1}+\mathrm{V}_{2}+\mathrm{V}_{3}+\right.$ $\left.\mathrm{V}_{4}+\ldots\right)$. Thus, the function $\mathrm{V}=\mathrm{f}(\mathrm{h})$ is created, describing the relationship between the volume of deformed rubber of the tread compound as a function of penetration depth. For aggressive pavements (with sharp-contour aggregate) the relation $V=f(h)$ is flatter than for pavements having rounded aggregate deeply embedded in the binder. 


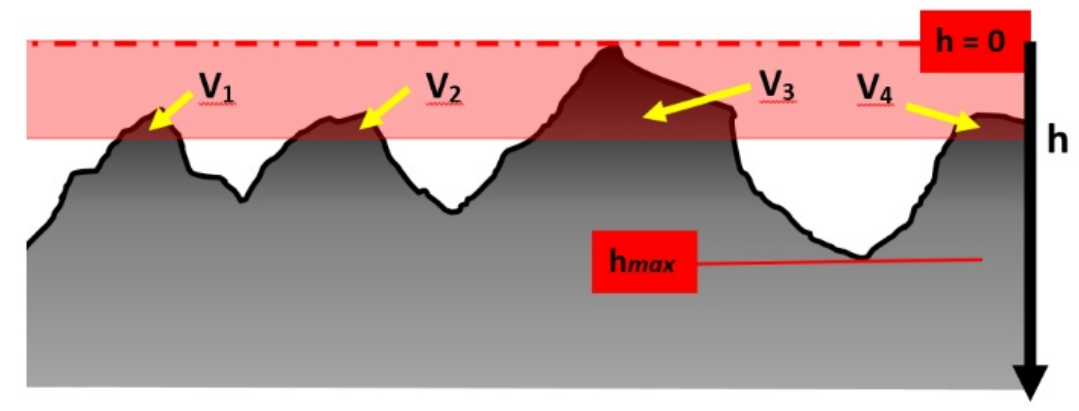

Figure 17. Explanation of proposed method of characterization of pavement texture in respect to rolling resistance.

In Figure 18 relations $V=f(h)$ acquired for SOFT, smooth tires are presented for pavements SMA8 and APS. The relations were obtained by two different methods. The first method, purely geometrical (described above), was based on the volume of summits that protrude over the horizontal plane placed at a distance " $\mathrm{h}$ " below the highest summit (see also Figure 17). Such a characteristic is easy to obtain on the base of a digital 3D texture profile. These relations are marked with solid lines. The second method accounted also for final shape of tread rubber "bridges" hanging over pots between the summits. These relations are marked with dashed lines. The principle of hanging "bridges" is explained also in Figure 19. Although the characteristics produced according to the second principle seem to be better correlated with actual tread deformations, they are more difficult to evaluate, as the shape of the bridges must be known (for example by molding technique). As the maximum tread penetration for the second method is known, the dashed lines end at the maximum penetration height. Looking at Figure 18, it can be seen that the maximum penetrations (in the case of SMA8 this is $1 \mathrm{~mm}$ and for APS it is $3.2 \mathrm{~mm}$ ) correspond to the volume of about $100 \mathrm{~mm}^{3}$ on curves which do not take into account the shape of the bridges.

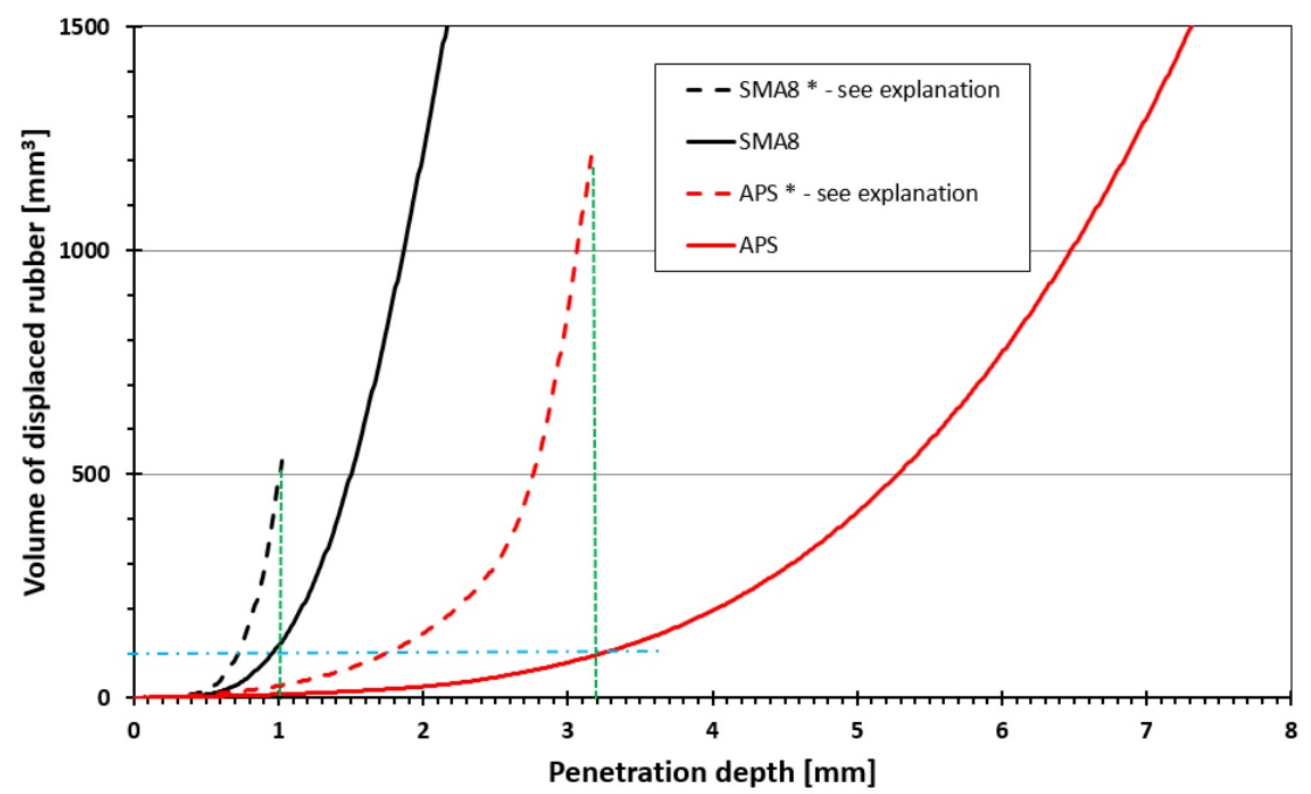

Figure 18. Relation between volume of deflected rubber and penetration depth for pavements SMA8 and APS. Solid lines show relations accounting only for geometrical shape of the texture while dashed lines account also for tread "bridges" deflection. 


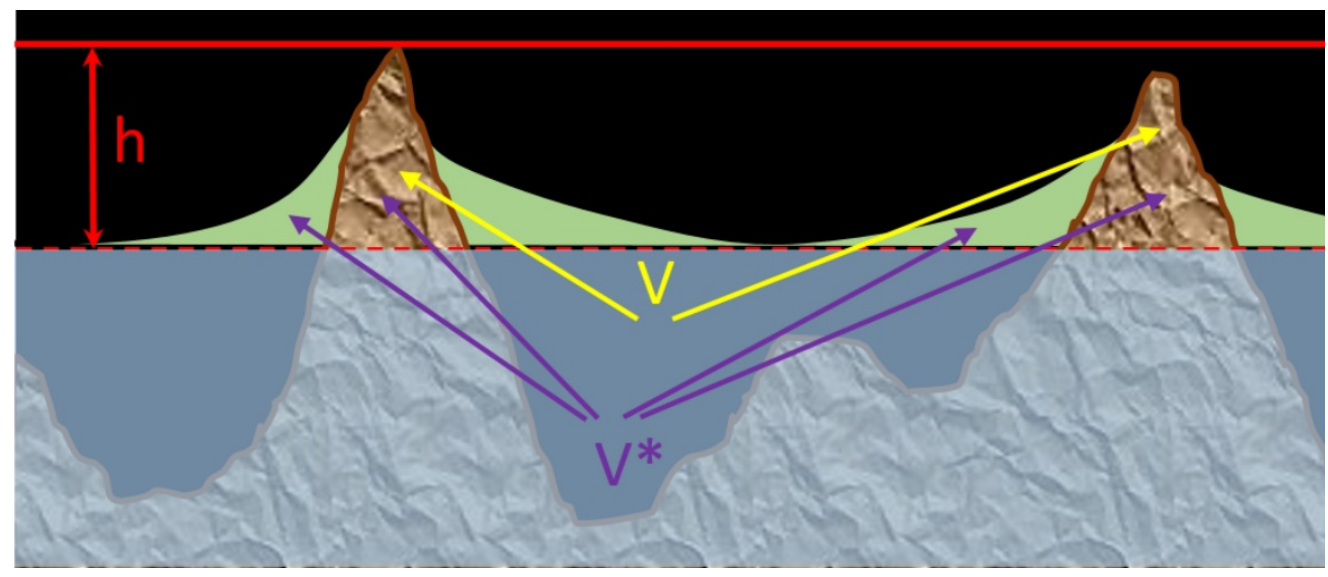

Figure 19. Relation between volume of deflected rubber and penetration depth for pavements SMA8 and APS.

A possible use of this observation is the adoption of the pavement rolling resistance classification based on the depth to which the texture must penetrate the tread to reach a certain volume of rubber displacement.

In order to simplify the procedure even more it would be desirable to attempt to base evaluation of the rubber deformation not on 3D texture characteristic, but on an easy to obtain 2D profile. Unfortunately, such simplification would not work in the case of directional textures like, for example, longitudinally grooved cement concrete; thus, the authors are in favor of 3D evaluations.

In the near future the authors plan to manufacture four replicas with very different geometrical patterns (evenly spaced spheres, cones, pyramids and cylinders), evaluate $\mathrm{V}=\mathrm{f}(\mathrm{h})$ characteristics for these replicas and make (as well as SMA8 and APS) rolling resistance tests of 20 different tires. This will verify the usefulness of the method based on the volume-depth characteristics.

Author Contributions: Conceptualization, J.E. and S.S.; measurements, S.S.; validation, S.S.; formal analysis, S.S.; writing, J.E.; visualization, J.E.; supervision, J.E.; funding acquisition, J.E. Both authors have read and agreed to the published version of the manuscript.

Funding: The research leading to these results has received funding from the Norway Grants 20142021 via the Polish National Centre for Research and Development. Article has been prepared within the frame of the project: "Improvement of the EU tire labelling system for noise and rolling resistance"-NOR/POLNOR/ELANORE/0001/2019-00 which is co-financed by program "Applied research" under the Norwegian Financial Mechanisms 2014-2021 POLNOR 2019-Energy, transport and climate.

Institutional Review Board Statement: Not applicable.

Informed Consent Statement: Not applicable.

Data Availability Statement: Data available on request.

Acknowledgments: The authors would like to acknowledge Grzegorz Ronowski and Wojciech Owczarzak for their contribution to measurements and evaluations.

Conflicts of Interest: The authors declare no conflict of interest. The funders had no role in the design of the study; in the collection, analyses, or interpretation of data; in the writing of the manuscript, or in the decision to publish the results.

\section{References}

1. Anon. Statistical Report 2018. Refining Products for Our Everyday Life; FuelsEurope: Brussels, Belgium, 2018. Available online: https:/ / www.fuelseurope.eu/wp-content/uploads/FuelsEurope-Statistical-Report-2018.pdf (accessed on 20 March 2021).

2. Ritchie, H.; Roser, M. Emissions by Sector. Our World in Data. Available online: https:/ / ourworldindata.org/emissions-by-sector (accessed on 20 March 2021). 
3. Ejsmont, J.; Swieczko-Zurek, B.; Ronowski, G.; Wilde, W.J. Rolling Resistance Measurements at the MnROAD Facility, Round 2. Center for Transportation Research and Implementation; Research Project Final Report 2014-29; Minnesota Department of Transportation: Saint Paul, MN, USA, 2014. Available online: http:/ / www.lrrb.org/pdf/201429.pdf (accessed on 20 March 2021).

4. Sandberg, U.; Bergiers, A.; Ejsmont, J.; Goubert, L.; Karlsson, R.; Zoller, M. Road Surface Influence on Tyre/Road Rolling Resistance; Reprt MIRIAM_SP1_04; Swedish Road and Transport Research Institute (VTI): Linköping, Sweden, 2011.

5. Sohaney, R.; Rasmussen, R.O. Pavement Texture Evaluation and Relationship to Rolling Resistance at MnROAD; Research Project Final Report 2013-16; Minnesota Department of Transportation: Saint Paul, MN, USA, 2013.

6. Goubert, L. State-of-the-Art Concerning Texture Influence on Skid Resistance, Noise Emission and Rolling Resistance; Project FP7-SST2013-RTD-1 ROSANNE; Deliverable D4.1: Woluwe-Saint-Lambert, Belgium, 2013.

7. Ejsmont, J.; Ronowski, G.; Swieczko-Zurek, B.; Sommer, S. Road texture influence on tyre rolling resistance. Road Mater. Pavement Des. 2017, 18, 181-198. [CrossRef]

8. Technical Committee: ISO/TC 43/SC 1. Characterization of Pavement Texture by Use of Surface Profiles-Part 1: Determination of Mean Profile Depth; ISO 13473-1; Technical Committee ISO/TC 43/SC 1: Geneva, Switzerland, 2019.

9. Willis, J.R.; Robbins, M.M.; Thompson, M. Effect of Pavement Properties on Vehicular Rolling Resistance: A Literature Review; Report 14-07; National Center for Asphalt Technology NCAT: Auburn, AL, USA, 2015. Available online: https://eng.auburn.edu/ research/centers/ncat/files/reports/2014/rep14-07.pdf (accessed on 20 March 2021).

10. Ydrefors, L.; Hjort, M.; Kharrazi, S.; Jerrelind, J.; Stensson Trigell, A. Rolling resistance and its relation to operating conditions: A literature review. J. Automob. Eng. 2021, 1-18. [CrossRef]

11. Pettinari, M.; Lund-Jansen, B.B.; Schmidt, B. Low Rolling Resistance Pavements in Denmark. In Proceedings of the E\&E Congress 2016 - 6th Eurasphalt \& Eurobitume Congress, Praque, Czech Republic, 1-3 June 2016. [CrossRef]

12. Ejsmont, J.; Sjogren, L.; Świeczko-Żurek, B.; Ronowski, G. Influence of road wetness on tire-pavement rolling resistance. J. Civ. Eng. Archit. 2015, 9, 1302-1310. [CrossRef]

13. Viera, T.; Sandberg, U.; Erlingsson, S. Negative texture, positive for the environment: Effects of horizontal grinding of asphalt pavements. Road Mater. Pavement Des. 2019, 22, 1-22. [CrossRef]

14. International Organization for Standardization. Passenger Car, Truck and Bus Tyres-Methods of Measuring Rolling Resistance-Single Point Test and Correlation of Measurement Results, 2nd ed.; ISO28580; International Organization for Standardization: Genève, Switzerland, 2018.

15. International Organization for Standardization. Passenger Car, Truck, Bus and Motorcycle Tyres-Methods of Measuring Rolling Resistance, 2nd ed.; ISO18164; International Organization for Standardization: Genève, Switzerland, 2005.

16. Society of Automotive Engineers. SAE Recommended Practice J2452_201707, Stepwise Coastdown Methodology for Measuring Tire Rolling Resistance; Society of Automotive Engineers: Warrendale, PA, USA, 2017.

17. Society of Automotive Engineers. SAE Recommended Practice J1269_201912, Rolling Resistance Measurement Procedure for Passenger Car, Light Truck, and Highway Truck and Bus Tires; Society of Automotive Engineers: Warrendale, PA, USA, 2019.

18. Bergiers, A.; Goubert, L.; Anfosso-Ledee, F.; Ejsmont, J.A.; Sandberg, U.; Zoller, M. MIRIAM: An International Round Robin Test to Compare Rolling Resistance Measurement Methods. 7th Symposium on Pavement Surface Characteristics SURF 2012; Virginia Tech Transportation Institute: Blacksburg, VA, USA, 2012.

19. Ejsmont, J.; Owczarzak, W. Engineering method of tire rolling resistance evaluation. Measurement 2019, 145, 144-149. [CrossRef]

20. Anon, Video Clip: “Can A Tire Have High Grip And Low Rolling Resistance?", Engineering Explained. Available online: https:/ / www.youtube.com/watch?v=oV_6u4Z5p-c\&ab_channel=Lesics (accessed on 8 May 2021). 